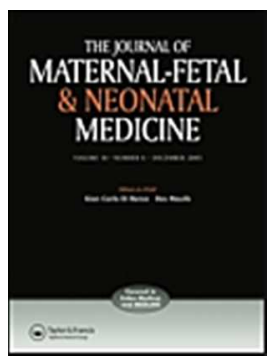

\title{
Progression of Doppler changes in early-onset small for gestational age fetuses. How frequent are the different progression sequences?
}

\begin{tabular}{|r|l|}
\hline Journal: & The Journal of Maternal-Fetal \& Neonatal Medicine \\
\hline Manuscript ID & DJMF-2017-0055.R1 \\
\hline Danuscript Type: & Original Paper \\
\hline Complete List of Authors: & $\begin{array}{l}\text { Morales-Roselló, José; Hospital Universitario y Politécnico La Fe, Servicio } \\
\text { de Obstetricia } \\
\text { Khalil, Asma; St George's Hospital, Fetal Medicine Unit } \\
\text { Fornés-Ferrer, Victoria; Instituto de Investigación Sanitaria La Fe, Unidad } \\
\text { de Bioestadística } \\
\text { Alberola-Rubio, José; Universidad Politécnica, } \\
\text { Grupo Bioelectrónica (I3BH) } \\
\text { Hervás Marín, David; Instituto de Investigación Sanitaria La Fe, Unidad de } \\
\text { Bioestadística } \\
\text { Peralta-LLorens, Nuria; Hospital Universitario y Politécnico La Fe, Servicio } \\
\text { de Epidemiología } \\
\text { Perales-Marín, Alfredo; Hospital Universitario y Politécnico La Fe, Servicio } \\
\text { de Obstetricia }\end{array}$ \\
\hline Keywords: & $\begin{array}{l}\text { Early-onset fetal growth restriction, small-for-gestational-age, umbilical } \\
\text { artery, fetal middle cerebral artery, ductus venosus }\end{array}$ \\
\hline \hline
\end{tabular}

\section{SCHOLARONE}

Manuscripts 


\title{
Progression of Doppler changes in early-onset small for gestational age fetuses. How frequent are the different progression sequences?
}

José Morales-Roselló ${ }^{\dagger}$, Asma Khalii", Victoria Fornés-Ferrer ${ }^{\dagger \dagger}$, José AlberolaRubio $^{* *}$, David Hervas-Marín ${ }^{\dagger \dagger}$, Núria Peralta Llorens ${ }^{* * *}$, Alfredo PeralesMarín.

${ }^{\dagger}$ Servicio de Obstetricia, Hospital Universitario y Politécnico La Fe, Valencia, Spain.

*Fetal Medicine Unit, St George's Hospital, London, UK.

*Grupo Bioelectrónica (I3BH), Universidad Politécnica, Valencia, Spain.

${ }^{\dagger+}$ Unidad de bioestadística, Instituto de Investigación Sanitaria La Fe, Valencia, Spain.

${ }^{* *}$ Servicio de Epidemiología, Hospital Universitario y Politécnico La Fe, Valencia, Spain.

\author{
Corresponding author: \\ Dr. José Morales-Roselló \\ Servicio de Obstetricia \\ Hospital Universitario y Politécnico La Fe \\ Avenida Fernando Abril Martorell 106 \\ 46026 Valencia, Spain \\ E-mail: jose.morales@uv.es
}




\section{Running Title:}

Progression of Doppler in early-onset fetal smallness.

Word count: Word count: 3052, Table count: 3, Figure count: 5.

13
14
15
16
17
18
19
20
21
22
23
24
25
26
27
28
29
30
31
32
33
34
35
36
37
38
39
40
41
42
43
44
45
46
47
48
49
50
51
52
53
54
55
56
57
58
59
60




\begin{abstract}
Objective: To evaluate the progression of Doppler abnormalities in earlyonset fetal smallness (SGA).
\end{abstract}

Methods: 948 Doppler examinations of the umbilical artery (UA), middle cerebral artery (MCA) and ductus venosus (DV), belonging to 405 early-onset SGA fetuses, were studied, evaluating the sequences of Doppler progression, the interval examination-labor at which Doppler became abnormal and the cumulative sum of Doppler anomalies in relation with labor proximity.

Results: The most frequent sequences were that in which only the UA pulsatility index $(\mathrm{PI})$ became abnormal $(42.1 \%)$ and that in which an abnormal UA PI appeared first, followed by an abnormal MCA PI (24.2\%). In general, $71.3 \%$ of the fetuses followed the classical progression sequence $U A \rightarrow M C A \rightarrow D V$, mostly in the early stages of growth restriction (84.1\%). In addition, the UA PI was the first parameter to be affected ( 9 weeks before delivery), followed by the MCA PI and the DV PIV (1 and 0 weeks). Finally, the UA PI began to sum anomalies 5 weeks before delivery, while the MCA and DV did it at 3 and 1 weeks before the pregnancy ended.

Conclusion: In early-onset SGA fetuses, Doppler progression tends to follow a predictable order, with sequential changes in the umbilical, cerebral and ductus venosus impedances. 


\section{KEY WORDS}

Early-onset fetal growth restriction, small-for-gestational-age, fetal hemodynamics, umbilical artery, fetal middle cerebral artery, ductus venosus.

URL: http://mc.manuscriptcentral.com/djmf Email: direnzo@unipg.it 


\section{INTRODUCTION}

Growth restriction imposes an adaptive burden on fetal hemodynamics, which aims to improve intrauterine survival ${ }^{1}$. This strain has been recently characterized and divided from a physiopathological point of view in two different conditions ${ }^{2}$. Late-onset fetal growth restriction (FGR) occurs more frequently, and is characterized by a state of nutritional imbalance with a preserved or mildly impaired placental function. The middle cerebral artery (MCA) Doppler and the cerebroplacental ratio (CPR) are usually the first to be affected in these pregnancies, while the umbilical artery (UA) Doppler pulsatility index $(\mathrm{PI})$ remains normal or mildly increased ${ }^{3}$. On the other extreme, early-onset FGR is initiated by placental dysfunction, resulting in anomalies of the UA blood flow, followed by changes in the MCA PI and the CPR in the so-called "brain-sparing phenomenon". If restriction progresses, the left ventricle becomes dominant, and the flow in the aortic isthmus becomes reverted. Finally, late adaptive changes include an increase in the ductus venosus pulsatility index of the vein (DV PIV), reflecting different degrees of cardiac failure, which in severe cases anticipate fetal death ${ }^{4-10}$.

This scenario of hemodynamic changes in early-onset fetal growth restriction was generally accepted for long as the most frequent. However it has been recently challenged ${ }^{11}$, suggesting that no specific sequence of Doppler progression among the participant vessels was more frequent than the other. The purpose of the study was to evaluate the progression of hemodynamic changes in small for gestational age (SGA) fetuses. 


\section{MATERIAL AND METHODS}

In a retrospective study, 948 Doppler examinations of the UA PI, MCA PI and DV PIV were performed between 24 and 33 weeks $\left(24^{+0}-33^{+6}\right.$ days $)$ in 405 early-onset SGA fetuses attending the ultrasound and prenatal diagnosis units of two tertiary centers in the UK (London) and Spain (Valencia). All fetuses had an estimated fetal weight (EFW) at examination below the $10^{\text {th }}$ centile according to Hadlock 4 formula ${ }^{12}$ and were delivered prior to 37 weeks' gestation $\left(36^{+6}\right.$ days). The birth weight of all these fetuses was confirmed to be below the $10^{\text {th }}$ centile at delivery. Fetuses affected with aneuploidy or major structural abnormalities were not included. As the object of the study was the evaluation of Doppler progression towards abnormal values, for every fetus and regardless of the number of examinations, we took into account only the first time the UA PI, MCA PI and DV PI crossed their abnormal percentiles $\left(>95^{\text {th }}\right.$ centile for the UA PI, $>95^{\text {th }}$ centile for the DV PIV and $<5^{\text {th }}$ centile for the MCA PI). We acknowledge this was not the only way to analyze data, however we considered this methodology depicted better the order of Doppler progression.

The limit percentile values were calculated for each week of gestational age (GA) according to the following formulas ${ }^{14-16}$ :

UA PI P95 $=2.6075-0.061129 * \mathrm{GA}+0.00057877 * \mathrm{GA}^{2}$

MCA PI P5 = -1.404152194 +0.209338699*GA $-0.003768618 * \mathrm{GA}^{2}$

DV PIV P95 $=0.69054+0.01431 * \mathrm{GA}-0.00035751 * \mathrm{GA}^{2}$

Where GA indicated the gestational age at examination expressed in weeks For every fetus, we studied the order in which the three Doppler parameters became abnormal and calculated for all fetuses the frequency of all possible 
combinations of Doppler progressions. In other words, the number of times a specific sequence of Doppler anomalies followed a specific order, including those in which only one, two or the three vessels were abnormal. Importantly, we considered the existence of an abnormal Doppler value when it was found abnormal for the first time, even though this parameter became normal in any of the following examinations, e.g. following the administration of steroids.

Management of cases with two or more abnormal Doppler parameters in the same examination.

In case that two or three Doppler parameters were abnormal at the same time the parameter that showed a higher statistical difference with its limit percentile was considered first in the sequence to become abnormal. This was also the methodology followed in fetuses with only one or with few examinations.

\section{Management of fetuses with only one examination}

Although we initially thought that only fetuses with multiple examinations could inform about Doppler progression (like small sequences of Doppler changes that could be collected and studied) in fact fetuses with only one examination were also interesting. The methodology applied to obtain information of progression in these cases used again the statistical differences with the respective abnormal percentiles to evaluate which Doppler parameter had earlier become abnormal.

For example: let us consider that in a fetus with only one examination at week 32 the DV Doppler was normal $(<p 95)$ and the UA and MCA Doppler were both abnormal (respectively >p95 and <p5). So the progression order could be either $U A \rightarrow M C A$ or $M C A \rightarrow U A$. In order to know which parameter had 
been the first to become abnormal we calculated the statistical difference with the respective limit percentile (the 5th percentile for the MCA, and the $95^{\text {th }}$ percentile for the UA Doppler). If the difference with this limit percentile was for example minimal in the UA Doppler, and more important in the MCA Doppler, this meant that the MCA had probably become abnormal earlier. Therefore, the sequence of activation in this fetus might be expressed as $M C A \rightarrow U A$.

This was done in all fetuses with a single examination, being these sequences incorporated to the general sum of sequences in order to evaluate the general order of Doppler progression. In fetuses with two or more examinations the same procedure was applied. However, in these cases only the first abnormal examination (the first time the Doppler value became abnormal) was taken into account.

We were aware that these calculations were based on statistical assumptions however as the errors were applicable to the three Doppler parameters, we considered that the final bias introduced in the total sum of Doppler progression represented just a small deviation from real order in fetuses with multiple examinations.

Apart from this general order, we also evaluated the frequency of fetuses with any abnormal Doppler, the frequency of fetuses following the classical sequence $(U A \rightarrow M C A \rightarrow D V)$ among those with any abnormal Doppler, the frequency of fetuses following the classical sequence among those showing initial hemodynamic changes (abnormal UA PI or MCA PI values), the frequency of fetuses following the classical sequence among those showing late hemodynamic changes (an abnormal DV PIV value) and finally, the 
frequency of cases with an abnormal DV PIV as the last parameter to be affected among those with an abnormal DV PIV.

Subsequently, in order to compare how the three parameters became abnormal in relation with the interval to delivery, we constructed three scattergrams in which the differences between the 948 UA PI, MCA PI and DV PIV values and their limit percentiles were plotted against the indicated interval. In this graphs we drew a line that represented the limit centile for each parameter (where the difference was equal to 0), and calculated three regression lines for the scattered values representing the $10^{\text {th }}, 50^{\text {th }}$ and $90^{\text {th }}$ percentiles. All these regression lines were constructed using splines to allow for non-linear relationships and taking into account that some of the values might have been longitudinally obtained in the same patient. In order to compare the three parameters, the $\mathrm{x}$-axis point where the median regression line crossed the limit centile line represented for each parameter the interval to delivery in which $50 \%$ of the fetuses became abnormal. These crossing points were used to compare the intervals among the three parameters.

Finally, a graph describing the cumulative sum of abnormal Doppler events in the 948 examinations was plotted against the interval to delivery. Three ascending lines representing the three Doppler parameters reflected how the sum of abnormal Doppler examinations grew in relation to this interval.

The work received an IRB authorization to perform retrospective studies. Statistical analysis and graphs were performed with R-Software ${ }^{\circledR} 3.2 .2$ (http://www.r-project.org/). The statistical significance was established at $p<0.05$. A search in PubMed was done, to identify previous citations reporting the sequence of changes in the UA, MCA and DV Doppler parameters in 
pregnancies complicated by SGA. Reference lists of relevant articles and reviews were hand searched for additional reports. The authors report no conflicts of interest. 


\section{RESULTS}

The total number of examinations was 948 , the total number of fetuses was 405 and the median (and interquartile range, IQR) GA at the first examination was 28.86 (27.14-31.43) weeks. All fetuses had at least one examination. Of these 157 (43.7\%), $89(24.8 \%), 42(11.7 \%), 26(7.2 \%), 13(3.6 \%), 11(3.1 \%)$, $7(2.0 \%), 5(1.4 \%), 4(1.1 \%), 1(0.3 \%), 3(0.8 \%)$ and $1(0.3 \%)$ were respectively examined $1,2,3,4,5,6,7,8,9,10,11$, and 16 times.

The descriptive statistics of the study population are shown in table 1 . The study group had a median (and IQR) maternal age of 30 (26-34) years a median GA at examination of 29.57 (28.14-31.71) weeks, a median GA at delivery of 31.79 (29.57-34) weeks, a median estimated fetal weight (EFW, according to Hadlock equation- $4^{12}$ ) of 890 (640-1230) g, a median BW of 1080 (750-1380) g, a median EFW ${ }^{12}$ centile of 0.09 (0.01-0.57), a median BW centile of $0.35(0.08-1.42)$ and a median interval examination-delivery of 1.28 (0.43-2.89) weeks.

The order in which the abnormal Doppler values were observed and the frequency of the sequences of Doppler progression is shown in table 2 and in figure 1. Of the 405 fetuses studied, $46(11.4 \%)$ did not present abnormal Doppler values, while 359 (88.6\%) showed at least one abnormal Doppler value in any of the examinations performed. Of the 359 fetuses that presented Doppler anomalies, the most frequent sequence for the appearance of abnormal Doppler values $(n=151,42.1 \%)$ was that in which only the UA PI was abnormal, the second $(n=87,24.2 \%)$ in which an abnormal UA PI appeared first, followed by an abnormal MCA PI and the third $(n=26,7.2 \%)$ in which an abnormal MCA PI appeared first followed by an abnormal UA PI. Of 
the 359 fetuses with any abnormal Doppler, 256 (71.3\%) presented progression orders that followed the classical sequence UA $\rightarrow M C A \rightarrow D V$, while $103(28.7 \%)$ did not. However, if we performed the analysis considering the existence of early (changes in the UA and MCA PI) or late hemodynamic changes (changes in the DV PIV), we found that those with early changes $(n=283)$ followed the classical sequence in a higher proportion of cases $(n=$ 238, 84.1\%). Conversely, when the DV was affected $(n=73)$, the classical sequence was much less frequent, and although in $64.4 \%(n=47)$ of these fetuses the DV PI remained as the last parameter to be abnormal, only a small proportion $(n=18 ; 24.7 \%)$ of abnormal DV PIV values were preceded by the full expected progression sequence.

Regarding the intervals to delivery, the percentile regressions drawn on the scattergrams which represented the differences between the Doppler values and the abnormal percentiles, showed that the UA PI was the first parameter to be affected, as $50 \%$ of the fetuses (represented by the median line or percentile $50^{\text {th }}$ regression line) showed abnormal UA PI values 9 weeks prior to delivery (figure $2 \mathrm{~A}$ ), while for the MCA PI this occurred 1 week before delivery (figure 2B) and for the DV PIV 0 days before delivery (figure 2C).

Finally, the graph describing the cumulative sum of abnormal Doppler events (figure 3) showed that the number of Doppler examinations crossing the limit percentile raised in the UA PI 8 weeks prior to delivery, while in the MCA and DV this was observed 3 weeks and one week before delivery, respectively The literature review revealed 8 studies in which the sequence of Doppler changes in pregnancies complicated by FGR was described. The details of these studies are shown in table 3. 


\section{DISCUSSION}

\section{Summary of findings}

The findings of this study suggest that the order of progression of Doppler abnormities in early-onset SGA follows a predictable pattern in the majority of cases. The hemodynamic changes start with an increase in the UA PI, followed by a reduction in the MCA PI, and an increase in the DV PIV. In $71.3 \%$ of cases the observed pattern fully coincides with the previously reported order, and this frequency rises to $84.1 \%$ if we consider the early hemodynamic changes (abnormal UA PI and MCA PI) only. Furthermore the Doppler changes in the UA are already seen in $50 \%$ of the patients 9 weeks before delivery. This was followed by Doppler changes in the MCA PI and DV, which were observed in $50 \%$ of the pregnancies one and 0 weeks prior delivery, respectively.

\section{$\underline{\text { Interpretation of these findings and comparison with existing literature }}$}

The initially described hemodynamic changes in early-onset SGA fetuses follow a pattern in which an early increase in the umbilical artery resistance, is followed by a mechanism of brain sparing with vasodilation of the MCA, and a further increase in the resistance in the DV, heralding the presence of brain sparing and cardiac failure ${ }^{4-10}$. This sequence of Doppler activations was recently challenged ${ }^{11}$ suggesting that no specific order predominated over the other. We have shown that in contrary to these last descriptions, the order of progression of Doppler abnormalities during FGR tends to follow a predictable order that coincides with the physiological order of experimental adaption to growth restriction ${ }^{17}$. 
Our study is in line with the earlier studies, reporting a common pattern of Doppler progression ${ }^{4-10}$, and differs from the conclusions shown in the PORTO study ${ }^{11}$ (Table 3 ). An explanation could be the different inclusion criteria in these studies. Our study included only pregnancies with suspected early-onset SGA (defined as EFW below the $10^{\text {th }}$ centile), which was confirmed to be SGA at birth (defined as BW below the $10^{\text {th }}$ centile). Furthermore, our fetuses were examined before 34 weeks and were delivered always before 37 weeks' gestation. Contrarily, the PORTO study included a mix of pregnancies with early and late-onset cases, which according to their data were frequently examined after 34 weeks and usually delivered after 37 weeks' gestation. This issue is of paramount importance, as the progression of Doppler changes is known to differ in both gestational intervals according to the different physiopathological mechanisms occurring in early and late-onset $\mathrm{FGR}^{18}$

\section{$\underline{\text { Clinical and research implications }}$}

Taking into account that the late stages in the sequence of Doppler deterioration are associated with a worse pregnancy outcome ${ }^{6,7}$, the existence of this predictable progression is crucial to schedule the frequency of the ultrasound assessments and plan parental counselling ${ }^{19}$. Although the aim of the study was the evaluation of the order of progression of Doppler abnormalities, we also included a mean interval value for comparison purposes among the three vessels and a cumulative sum of first time Doppler abnormalities. Interestingly, our results were in line with the findings of previous studies, especially those which aimed to calculate these intervals and cumulative sums in a more accurate way ${ }^{4,20,21}$. 
Two other interesting findings could also be highlighted in our study. One is that the presence of an abnormal MCA PI occurs on average much later that earlier described ${ }^{20}$, when the UA impedance is already abnormal, a finding in line with an earlier work published by our group ${ }^{22}$. The other is that the expected sequence of Doppler progression seems to vary depending on the stage of hemodynamic compensation. In fact, fetuses affected with early Doppler changes (UA PI or MCA PI) tend to maintain more frequently the predicted classical sequence $(84.1 \%)$ than those at the end of the hemodynamic compensation (abnormal DV PIV) (24.7\%). Considering that the presence of an abnormal DV has proven to be the best Doppler predictor of fetal acidosis, and postnatal neurocognitive impairment ${ }^{23-24}$, our study underlines that an abnormal DV PIV might not be always preceeded by an abnormal UA PI followed by an abnormal MCA PI, and could be, for example, directly preceded by an abnormal UA PI without the presence of an abnormal MCA PI $(\mathrm{N}=21,5.8 \%)$. This issue is however minimized by the fact that 47 $(64.4 \%)$ of the 73 cases with an abnormal DV Doppler, presented it as the last parameter to be affected, and therefore the presence of an abnormal DV PI should still be considered as a sign of late hemodynamic dysfunction.

\section{Strengths and weaknesses}

Our study is the first to study Doppler progression from a double perspective; the order of appearance of Doppler abnormalities regardless of GA and time intervals, and the analysis of Doppler abnormalities in relation to the examination-to-delivery interval. We consider that this combined approach provided more robust assessment in order to evaluate the progression of fetal hemodynamics. Furthermore, our study focused on early-onset smallness by 
including pregnancies with EFW less than $10^{\text {th }}$ centile before 34 weeks' gestation. However, we did not include other Doppler parameters such as the aortic isthmus or the myocardial performance index ${ }^{20,21}$. Unfortunately, these data were not available in the majority of the cases. Also, we defined the existence of an abnormal Doppler value when it was found abnormal for the first time, even though it became normal afterwards in the follow-up, a discrepancy that could be due to the use of corticosteroids for lung maturation, which is known to influence the Doppler values ${ }^{24}$ or directly due to technical or intra and inter-observer measurement errors. We recognize that this might cause biases in the calculation of frequencies and sequences of Doppler abnormalities. However, the fact that all the parameters (UA, MCA and DV) were affected similarly by the same circumstances would diminish the possibility of systematic bias. Finally, considering the order of Doppler progression, we considered that a parameter was affected first when statistically its value was further away from the limit percentile. We were aware that this was only a mathematical approach. However the bias was again minimized considering that the possible error would be equally distributed among the three parameters. In addition, from a methodological point of view, it was the only way to analyze much of the data, as not infrequently two different parameters were found to be affected at unison in the same examination.

\section{$\underline{\text { Conclusion }}$}

As observed in earlier animal experimentation ${ }^{17}$ and in earlier human observational studies $^{4-9}$, the progression order of Doppler abnormalities in early-onset smallness tends to follow a predictable order, with an increase in 
UA PI followed by a decrease in the MCA PI and an abnormal DV PIV. In one third of cases however, variations may occur, especially in the latter stages of fetal adaptation, when the DV Doppler is involved. More studies are needed to elucidate the cause of those exceptional Doppler progression patterns. 


\section{REFERENCES}

1. Verburg BO, Jaddoe VW, Wladimiroff JW, Hofman A, Witteman JC, Steegers EA. Fetal hemodynamic adaptive changes related to intrauterine growth: the Generation R Study. Circulation. 2008;117:649-59.

2. Figueras F, Gratacós E. Update on the diagnosis and classification of fetal growth restriction and proposal of a stage-based management protocol. Fetal Diagn Ther. 2014;36:86-98.

3. Morales-Roselló J, Khalil A, Perales-Marín A. The PORTO study and the importance of cerebroplacental ratio in fetalgrowth restriction. Am J Obstet Gynecol. 2015;212:551-2.

4. Ferrazzi E, Bozzo M, Rigano S, Bellotti M, Morabito A, Pardi G, Battaglia FC, Galan HL. Temporal sequence of abnormal Doppler changes in the peripheral and central circulatory systems of the severely growth-restricted fetus. Ultrasound Obstet Gynecol. 2002;19:140-6.

5. Baschat $A A$, Gembruch $U$, Harman $C R$. The sequence of changes in Doppler and biophysical parameters as severe fetal growth restriction worsens. Ultrasound Obstet Gynecol. 2001;18:571-7.

6. Baschat AA, Gembruch U, Reiss I, Gortner L, Weiner CP, Harman CR. Relationship between arterial and venous Doppler and perinatal outcome in fetal growthrestriction. Ultrasound Obstet Gynecol. 2000;16:407-13.

7. Ozcan T, Sbracia M, d'Ancona RL, Copel JA, Mari G. Arterial and venous Doppler velocimetry in the severely growth-restricted fetus and associations with adverse perinatal outcome. Ultrasound Obstet Gynecol. 1998;12:39-44.

8. Turan OM, Turan S, Gungor S, Berg C, Moyano D, Gembruch U, Nicolaides $\mathrm{KH}$, Harman $\mathrm{CR}$, Baschat AA. Progression of Doppler 
abnormalities in intrauterine growth restriction. Ultrasound Obstet Gynecol. 2008;32:160-7.

9. Machlitt A, Wauer RR, Chaoui R. Longitudinal observation of deterioration of Doppler parameters, computerized cardiotocogram and clinical course in a fetus with growth restriction. J Perinat Med. 2001;29:71-6.

10. Hecher K, Bilardo CM, Stigter RH, Ville Y, Hackelöer BJ, Kok HJ, Senat $\mathrm{MV}$, Visser $\mathrm{GH}$. Monitoring of fetuses with intrauterine growth restriction: a longitudinal study. Ultrasound Obstet Gynecol. 2001;18:564-70.

11. Unterscheider J, Daly S, Geary MP, Kennelly MM, McAuliffe FM, O'Donoghue K, Hunter A, Morrison JJ, Burke G, Dicker P, Tully EC, Malone FD. Predictable progressive Doppler deterioration in IUGR: does it really exist? Am J Obstet Gynecol. 2013;209:539.e1-7.

12. Hadlock FP, Harrist RB, Sharman RS, Deter RL, Park SK. Estimation of fetal weight with the use of head, body, and femur measurements- a prospective study. Am J Obstet Gynecol. 1985;151:333-7.

13. Yudkin PL, Aboualfa M, Eyre JA, Redman CW, Wilkinson AR. New birthweight and head circumference centiles for gestational ages $\quad 24$ to 42 weeks. Early Hum Dev 1987;15:45-52.

14. Acharya G, Wilsgestational ageard T, Berntsen GK, Maltau JM, Kiserud T. Reference ranges for serial measurements of umbilical artery Doppler indices in the second half of pregnancy. Am J Obstet Gynecol 2005;192:937-44.

15. Morales-Roselló J, Khalil A, Morlando M, Hervás-Marín D, Perales-Marín A. Doppler reference values of the fetal vertebral and middle cerebral arteries, at 19-41 weeks gestation. J Matern Fetal Neonatal Med. 2015;28:338-43. 
16. Kessler J, Rasmussen S, Hanson M, Kiserud T. Longitudinal reference ranges for ductus venosus flow velocities and waveform indices. Ultrasound Obstet Gynecol. 2006;28:890-8.

17. López-Tello J, Barbero A, González-Bulnes A, Astiz S, Rodríguez M, Formoso-Rafferty N, Arias-Álvarez M, Rebollar PG. Characterization of early changes in fetoplacental hemodynamics in a diet-induced rabbit model of IUGR. J Dev Orig Health Dis. 2015;6:454-61.

18. Morales-Roselló J, Khalil A. Fetal cerebroplacental ratio and adverse perinatal outcome. J Perinat Med. 2016;44:355.

19. Baschat AA, Hecher K. Fetal growth restriction due to placental disease. Semin Perinatol. 2004;28:67-80.

20. Figueras F, Benavides A, Del Rio M, Crispi F, Eixarch E, Martinez JM, Hernandez-Andrade E, Gratacós E. Monitoring of fetuses with intrauterine growth restriction: longitudinal changes in ductus venosus and aortic isthmus flow. Ultrasound Obstet Gynecol. 2009;33:39-43.

21. Cruz-Martinez R, Figueras F, Benavides-Serralde A, Crispi F, HernandezAndrade E, Gratacos E. Sequence of changes in myocardial performance index in relation to aortic isthmus and ductus venosus Doppler in fetuses with early-onset intrauterine growth restriction. Ultrasound Obstet Gynecol. 2011;38:179-84.

22. Morales Roselló J, Hervás Marín D, Perales Marín A, López Fraile S. Doppler study of the fetal vertebral and middle cerebral arteries in fetuses with normal and increased umbilical artery resistance indices. $J$ Clin Ultrasound. 2013;41:224-9. 
23. Lees CC, Marlow N, van Wassenaer-Leemhuis A, Arabin B, Bilardo CM, Brezinka C, Calvert S, Derks JB, Diemert A, Duvekot JJ, Ferrazzi E, Frusca T, Ganzevoort W, Hecher K, Martinelli P, Ostermayer E, Papageorghiou AT, Schlembach D, Schneider KT, Thilaganathan B, Todros T, Valcamonico A, Visser GH, Wolf H; TRUFFLE study group. 2 year neurodevelopmental and intermediate perinatal outcomes in infants with very preterm fetal growth restriction (TRUFFLE); a randomized trial. Lancet. 2015 30;385:2162-72.

24. Lees C, Marlow N, Arabin B, Bilardo CM, Brezinka C, Derks JB, Duvekot J, Frusca T, Diemert A, Ferrazzi E, Ganzevoort W, Hecher K, Martinelli P, Ostermayer E, Papageorghiou AT, Schlembach D, Schneider KT, Thilaganathan B, Todros $T$, van Wassenaer-Leemhuis A, Valcamonico A, Visser $\mathrm{GH}$, Wolf $\mathrm{H}$; TRUFFLE Group. Perinatal morbidity and mortality in early-onset fetal growth restriction: cohort outcomes of the trial of randomized umbilical and fetal flow in Europe (TRUFFLE). Ultrasound Obstet Gynecol. 2013;42:400-8.

25. Nozaki AM, Francisco RP, Fonseca ES, Miyadahira S, Zugaib M. Fetal hemodynamic changes following maternal betamethasone administration in pregnancies with fetal growth restriction and absent end-diastolic flow in the umbilical artery. Acta Obstet Gynecol Scand. 2009;88:350-4. 
Figure 1. Sequence of progression for Doppler anomalies observed in the studied group of small-forgestational age fetuses. $71 \%$ of cases coincided with the progressive sequence of abnormal values in the UA PI, MCA PI and DV PIV. Exceptions to this scenario occur mostly in the last stages of the hemodynamic progression. figure 1 $141 \times 100 \mathrm{~mm}(300 \times 300 \mathrm{DPI})$ 
Figure 2A. Observed UA PI values - UA PI 95th centile. 0 line represents those values at the limit of normality. As soon as eight weeks before the end of pregnancy half of the fetuses already present anomalies in the UA PI. figure $2 \mathrm{a}$ $133 \times 90 \mathrm{~mm}(300 \times 300 \mathrm{DPI})$

URL: http://mc.manuscriptcentral.com/djmf Email: direnzo@unipg.it 
Figure 2B. Observed MCA PI values - MCA PI 5th centile. 0 line represents those values at the limit of normality. One week before the end of pregnancy half of the fetuses present anomalies in the MCA PI. figure $2 b$

$133 \times 90 \mathrm{~mm}(300 \times 300$ DPI $)$

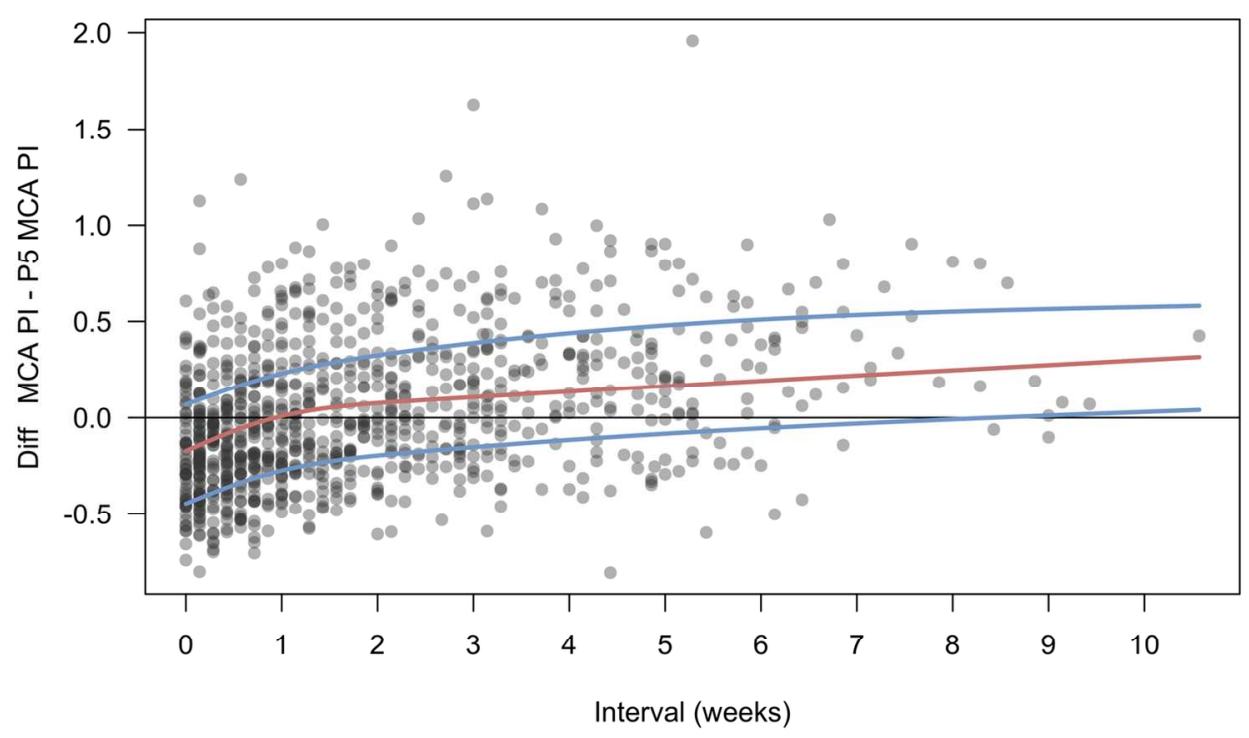

URL: http://mc.manuscriptcentral.com/djmf Email: direnzo@unipg.it 
Figure 2C. Observed DV PI values - DV PI 95th centile. 0 line represents those values at the limit of normality. At the end of pregnancy half of the fetuses already present anomalies in the DV PI. figure $2 \mathrm{c}$ $133 \times 90 \mathrm{~mm}(300 \times 300 \mathrm{DPI})$ 
Figure 3. Cumulative sum of Doppler anomalies along the interval to delivery. The UA was the parameter in which the abnormal percentile was sooner and most frequently crossed, followed by the MCA and the DV. The increase of Doppler examinations crossing the limit percentile appeared in the UA PI as soon as 8 weeks prior to delivery, while in the MCA and DV this was respectively observed 3 and 1 weeks before the end of pregnancy.

figure 3

$133 \times 90 \mathrm{~mm}(300 \times 300$ DPI $)$

URL: http://mc.manuscriptcentral.com/djmf Email: direnzo@unipg.it 
Table 1.

Description of the study group

\begin{tabular}{|c|c|}
\hline Parameter & Median (IQR) or $\mathbf{N}(\%)$ \\
\hline Age (years) & $30(26-34)$ \\
\hline Gestational age at examination (weeks) & $29.57(28.14-31.71)$ \\
\hline Gestational age at delivery & $31.79(29.57-34)$ \\
\hline EFW (Hadlock-4) (grams) & $890(640-1230)$ \\
\hline BW (grams) & $1080(750-1380)$ \\
\hline EFW (Hadlock-4) centile & $0.09(0.01-0.57)$ \\
\hline BW centile & $0.35(0.08,1.42)$ \\
\hline Interval examination-delivery (weeks) & $1.28(0.43,2.89)$ \\
\hline Gestational age at the $1^{\text {st }}$ examination (weeks) & $28.86(27.14-31.43)$ \\
\hline Examinations (total) & 948 \\
\hline Fetuses (total) & 405 \\
\hline Fetuses with no abnormal Doppler & $46(11.4 \%)$ \\
\hline Fetuses with any abnormal Doppler & $359(88,6 \%)$ \\
\hline Fetuses with 1 examination & $157(43.73)$ \\
\hline Fetuses with 2 examinations & 89 (24.79) \\
\hline Fetuses with 3 examinations & $42(11.70)$ \\
\hline Fetuses with 4 examinations & $26(7.24)$ \\
\hline Fetuses with 5 examinations & $13(3.62)$ \\
\hline Fetuses with 6 examinations & $11(3.06)$ \\
\hline Fetuses with 7 examinations & $7(1.95)$ \\
\hline Fetuses with 8 examinations & $5(1.39)$ \\
\hline Fetuses with 9 examinations & $4(1.11)$ \\
\hline Fetuses with 10 examinations & $1(0.28)$ \\
\hline Fetuses with 11 examinations & $3(0.84)$ \\
\hline Fetuses with 16 examinations & $1(0.28)$ \\
\hline
\end{tabular}


Table 2

Progression pattern for the Doppler anomalies in the UA, MCA and DV; percentage of progression for the different sequences.

\begin{tabular}{|c|c|c|}
\hline Sequence & $\mathbf{N}$ & Frequency \\
\hline Total early-onset small fetuses $(E F W<p 10)$ & 405 & $100.00 \%$ \\
\hline No abnormal Doppler found in the follow-up & 46 & $11.36 \%$ \\
\hline Any abnormal Doppler found in the follow-up & 359 & $88.64 \%$ \\
\hline UA alone & 151 & $42.06 \%$ * \\
\hline $\mathrm{UA} \rightarrow \mathrm{MCA}$ & 87 & $24.23 \%$ * \\
\hline$M C A \rightarrow U A$ & 26 & $7.24 \%$ * \\
\hline$U A \rightarrow D V$ & 21 & $5.84 \%$ * \\
\hline MCA alone & 19 & $5.29 \%$ * \\
\hline$U A \rightarrow M C A \rightarrow D V$ & 18 & $5.01 \%$ * \\
\hline$U A \rightarrow D V \rightarrow M C A$ & 15 & $4.17 \%$ * \\
\hline $\mathrm{DV} \rightarrow \mathrm{MCA}$ & 4 & $1.11 \%$ * \\
\hline $\mathrm{DV} \rightarrow \mathrm{UA}$ & 4 & $1.11 \%$ * \\
\hline$M C A \rightarrow U A \rightarrow D V$ & 3 & $0.83 \%$ * \\
\hline $\mathrm{MCA} \rightarrow \mathrm{DV}$ & 3 & $0.83 \%$ * \\
\hline DV alone & 2 & $0.56 \%$ * \\
\hline $\mathrm{MCA} \rightarrow \mathrm{DV} \rightarrow \mathrm{UA}$ & 1 & $0.28 \%$ * \\
\hline $\mathrm{DV} \rightarrow \mathrm{UA} \rightarrow \mathrm{MCA}$ & 1 & $0.28 \%$ * \\
\hline $\mathrm{DV} \rightarrow \mathrm{MCA} \rightarrow \mathrm{UA}$ & 1 & $0.28 \%$ * \\
\hline $\begin{array}{l}\text { Sequences following the classical sequence } \\
\text { among those with any abnormal Doppler } \\
\text { (UA alone, UA } \rightarrow \text { MCA, UA } \rightarrow \text { MCA } \rightarrow \text { DV) }\end{array}$ & 256 & $71.31 \%^{*}$ \\
\hline $\begin{array}{l}\text { Sequences not following the classical sequence } \\
\text { among those with any abnormal Doppler } \\
(U A \rightarrow D V, M C A \text { alone, MCA } \rightarrow \cup A \text {, } \\
U A \rightarrow D V \rightarrow M C A, D V \text { alone, DV } \rightarrow \text { MCA, } \\
D V \rightarrow U A, M C A \rightarrow U A \rightarrow D V, M C A \rightarrow D V, \\
M C A \rightarrow D V \rightarrow U A, D V \rightarrow U A \rightarrow M C A, \\
D V \rightarrow M C A \rightarrow U A)\end{array}$ & 103 & $28.69 \% *$ \\
\hline $\begin{array}{l}\text { Sequences following the classical sequence in } \\
\text { early stages of hemodynamic dysfunction } \\
\text { (abnormal Doppler in the UA or MCA, } N=283 \text { ). } \\
\text { (UA alone, UA } \rightarrow \text { MCA) }\end{array}$ & 238 & $84.10 \%^{\dagger}$ \\
\hline $\begin{array}{l}\text { Sequences not following the classical sequence } \\
\text { in early stages of hemodynamic dysfunction } \\
\text { (abnormal Doppler in the UA or MCA, N=283). } \\
\text { (MCA alone, MCA } \rightarrow \text { UA) }\end{array}$ & 45 & $15.90 \%{ }^{\dagger}$ \\
\hline $\begin{array}{l}\text { Sequences following the classical sequence in } \\
\text { late stages of hemodynamic compensation } \\
\text { (abnormal Doppler in the DV, } N=73 \text { ). } \\
(U A \rightarrow M C A \rightarrow D V)\end{array}$ & 18 & $24.66 \%{ }^{\mathrm{T}}$ \\
\hline 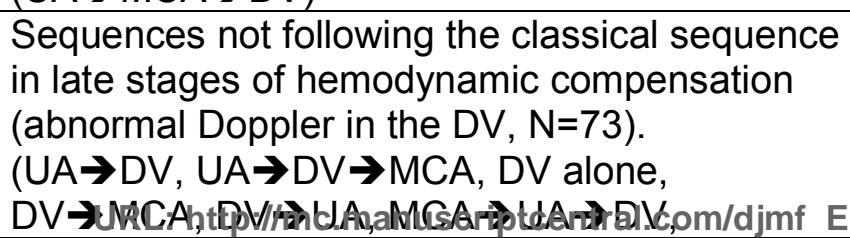 & 55 & $75.34 \%{ }^{\dagger \dagger}$ \\
\hline
\end{tabular}


Notes: UA=umbilical artery Doppler, $\mathrm{MCA}=$ middle cerebral artery Doppler, $D V=$ ductus venosus Doppler, $p=$ percentile, *indicated percentage refers only to cases with any abnormal Doppler $(\mathrm{N}=359)$, tindicated percentage refers only to early stages of hemodynamic dysfunction (abnormal Doppler in the UA or MCA) $(\mathrm{N}=283)$, ${ }^{\dagger \dagger}$ indicated percentage refers only to late stages of hemodynamic dysfunction (abnormal Doppler in the DV) $(\mathrm{N}=73),{ }^{+}$indicated percentage refers only to fetuses with an abnormal Doppler in the DV $(\mathrm{N}=73)$. 
1 Table 3

2

3Comparison among the different studies evaluating either Doppler progression or the sequence of changes followed by the different Doppler parameters.

4

5

\begin{tabular}{|c|c|c|c|c|c|c|c|c|c|c|c|c|}
\hline $\begin{array}{l}6^{\text {Study }} \\
7\end{array}$ & $\mathbf{N}$ & $\begin{array}{l}\text { GA at } \\
\text { exam } \\
\text { (weeks) }\end{array}$ & $\begin{array}{l}\text { GA at delivery } \\
\text { (weeks) }\end{array}$ & $\begin{array}{l}\text { Inclusion } \\
\text { criteria }\end{array}$ & $\begin{array}{l}\text { Vessels } \\
\text { examined }\end{array}$ & $\begin{array}{l}\text { Other } \\
\text { exams }\end{array}$ & $\begin{array}{l}\text { Interval } \\
\text { exam. }\end{array}$ & $\begin{array}{l}\begin{array}{l}\text { Number } \\
\text { exams per } \\
\text { fetus }\end{array} \\
\end{array}$ & \begin{tabular}{|ll}
$\begin{array}{l}\text { Criteria } \\
\text { abnormal } \\
\text { Doppler }\end{array}$ & for \\
\end{tabular} & $\begin{array}{l}\text { Finalization } \\
\text { of pregnancy } \\
\text { criteria }\end{array}$ & Method of analysis & Conclusions \\
\hline $\begin{array}{l}8 \text { Ozcan et al }^{7} \\
9 \text { 1998 } \\
10 \\
\end{array}$ & 19 fetuses & $26.4-31.4$ & $27-32$ & EFW $<\mathrm{P}^{\text {th }}$ & $\begin{array}{l}\text { UA, MCA, } \\
\text { DV, UV }\end{array}$ & CTG & $\begin{array}{l}\text { No interval } \\
(1 \\
\text { measurement } \\
\text { only) }\end{array}$ & \begin{tabular}{|l|}
1 (the last) \\
\end{tabular} & $\begin{array}{l}\text { First measurement } \\
\text { abnormal }\end{array}$ & $\begin{array}{l}\text { Abnormal } \\
\text { CTG }\end{array}$ & $\begin{array}{l}\text { Association of arterial } \\
\text { and venous Doppler } \\
\text { parameters with perinatal } \\
\text { outcome }\end{array}$ & $\begin{array}{l}\text { DV Doppler was the only parameter } \\
\text { associated with perinatal death and } \\
\text { low 5'Apgar score }\end{array}$ \\
\hline $\begin{array}{l}1 \text { 1Baschat et al }^{6} \\
12^{000} \\
13\end{array}$ & $\begin{array}{l}121 \\
\text { fetuses }\end{array}$ & $\begin{array}{l}\text { Not } \\
\text { indicated }\end{array}$ & $\begin{array}{l}24-40 \\
\text { G1: } 27-40 \\
\text { G2: } 27-37 \\
\text { G3: } 24-37\end{array}$ & $\begin{array}{l}\text { AC }<\text { P5 }{ }^{\text {th }}+ \\
\text { abnormal } \mathrm{UA} \\
\text { PI. BW } \mathrm{BW}<\mathrm{P} 10^{\text {th }}\end{array}$ & $\begin{array}{l}\text { UA, MCA, } \\
\text { DV, IVC, UV }\end{array}$ & $\begin{array}{l}\text { CTG, } \\
\text { BPS }\end{array}$ & Not indicated & At least 2 & $\begin{array}{l}\text { First measurement } \\
\text { abnormal }^{\dagger}\end{array}$ & $\begin{array}{l}\text { Abnormal } \\
\text { CTG and BPS }\end{array}$ & $\begin{array}{l}\text { Classification of fetuses } \\
\text { in } 3 \text { groups according to } \\
\text { Doppler findings with } \\
\text { outcome comparison }\end{array}$ & $\begin{array}{l}\text { Progression of Doppler changes } \\
\text { exists: 1-UA, 2-MCA, 3-DV. } \\
\text { Outcome depends on progression. }\end{array}$ \\
\hline $\begin{array}{l}14 \text { Baschat et al } \\
15^{5001} \\
16 \\
17\end{array}$ & $\begin{array}{l}236 \\
\text { fetuses } \\
44 \quad \text { with } \\
\text { abnormal } \\
\text { BPS }\end{array}$ & $\begin{array}{l}\text { 16-37 } \\
\text { Entry at: } \\
\text { 16-31, Last } \\
\text { exam: 24- } \\
37\end{array}$ & $\begin{array}{l}\text { 25-37 } \\
\text { (Stillbirth: 25- } \\
28, \quad \text { livebirths: } \\
26-37 \text { ) }\end{array}$ & $\begin{array}{l}\mathrm{AC}<\mathrm{P}^{\mathrm{th}}+ \\
\text { abnormal } \mathrm{UA} \\
\text { PI. BW } \mathrm{BW} 10^{\text {th }}\end{array}$ & $\begin{array}{l}\text { UA, MCA, } \\
\text { DV, IVC, UV }\end{array}$ & $\begin{array}{l}\text { CTG, } \\
\text { BPS }\end{array}$ & $\begin{array}{l}\text { 1-14 days, } \\
\text { daily the last } \\
\text { week }\end{array}$ & $4-17$ & $\begin{array}{l}\text { First measurement } \\
\text { abnormal }^{\dagger}\end{array}$ & $\begin{array}{l}\text { Abnormal } \\
\text { BPS, CTG }\end{array}$ & $\begin{array}{l}\text { Percentage of abnormal } \\
\text { Doppler findings. } \\
\text { Frequencies for Doppler } \\
\text { deterioration sequences, } \\
\text { progression interval }\end{array}$ & $\begin{array}{l}\text { UA-MCA-DV sequence occurs in } \\
73 \% \text { of cases. In } 64 \% \text { with the full } \\
\text { sequence. } \\
\text { BPS deteriorates at the end of the } \\
\text { sequence. }\end{array}$ \\
\hline $\begin{array}{l}1 \text { fHecher et al }^{10} \\
19^{2001} \\
20 \\
21 \\
22 \\
23\end{array}$ & $\begin{array}{l}547 \\
\text { exams, } 93 \\
\text { fetuses } \\
\text { with at } \\
\text { least } 3 \\
\text { exams } \\
24 \mathrm{~h} \text { prior } \\
\text { to delivery }\end{array}$ & $\begin{array}{l}24-40 \\
\text { Entry at: } \\
24-34\end{array}$ & \begin{tabular}{|l|}
$24-40$ \\
Group $1(24-31)$ \\
Group $2(32-40)$
\end{tabular} & $\mathrm{AC}<\mathrm{P}^{\text {th }}$ & $\begin{array}{l}\text { UA, DT-Ao, } \\
\text { MCA, DV, } \\
\text { IVC }\end{array}$ & CTG & $\begin{array}{l}1-7 \text { days } \\
\text { depending on } \\
\text { Doppler } \\
\text { findings }\end{array}$ & $\begin{array}{l}3-27 \\
\text { (At least 3) }\end{array}$ & $\begin{array}{l}\text { First measurement } \\
\text { abnormal }\end{array}$ & $\begin{array}{l}\text { CTG, } \\
\text { Attending } \\
\text { obstetrician } \\
\text { discretion }\end{array}$ & $\begin{array}{l}\text { Patterns of progression: } \\
\text { GA at onset, interval to } \\
\text { delivery, progression } \\
\text { intervals, classification } \\
\text { in } 2 \text { groups with } \\
\text { outcome comparison }\end{array}$ & $\begin{array}{l}\text { Temporal sequence of changes } \\
\text { exist: 1-UA, 2-MCA, 3-DV. } \\
\text { Outcome depends on progression, } \\
\text { DV and CTG are the best predictors } \\
\text { of mortality }\end{array}$ \\
\hline $\begin{array}{l}24^{\text {Ferrazzi et al }}{ }^{4} \\
25^{2002} \\
26 \\
27\end{array}$ & 26 fetuses & $\begin{array}{l}<32-34 \\
\text { Entry }<32 \\
\text { weeks, } \\
\text { followed } \\
\text { until } 34 \\
\text { weeks }\end{array}$ & $26-34$ & $\begin{array}{l}\mathrm{AC}<\mathrm{P}^{\text {nd }} \\
\text { abnormal UA } \\
\text { PI, abnormal } \\
\text { Ut PI }\end{array}$ & $\begin{array}{l}\text { UA, MCA, } \\
\text { UtA, DV, Ao- } \\
\text { OT, P-OT }\end{array}$ & CTG & 2 per week & $\begin{array}{l}\text { Not } \\
\text { indicated }\end{array}$ & $\begin{array}{l}\text { Two or more } \\
\text { consecutive } \\
\text { abnormal } \\
\text { measurements }\end{array}$ & $\begin{array}{l}\text { CTG, } \\
\text { exclusion of } \\
\text { pregnancies } \\
\text { with maternal } \\
\text { causes to } \\
\text { finalize }\end{array}$ & $\begin{array}{l}\text { Cumulative onset time } \\
\text { curves of Doppler } \\
\text { anomalies, interval to } \\
\text { delivery. Outcome } \\
\text { according to progression }\end{array}$ & $\begin{array}{l}\text { Temporal sequence of changes } \\
\text { exist: 1-UA and Ut, 2-MCA, 3-DV. } \\
\text { Outcome depends on progression. } \\
\text { Late changes are the best predictors } \\
\text { of adverse outcome. }\end{array}$ \\
\hline $\begin{array}{l}28 \text { Puran et al } \\
29008 \\
30 \\
31\end{array}$ & $\begin{array}{l}668 \\
\text { Doppler } \\
\text { exams, } \\
104 \\
\text { fetuses }\end{array}$ & \begin{tabular}{|l|}
$23-33$ \\
\end{tabular} & $26-40$ & $\begin{array}{l}\mathrm{AC}<\mathrm{P} 5^{\text {th }}+ \\
\text { abnormal UA } \\
\text { PI or CPR. } \\
\text { BW }<\text { P1 } 10^{\text {th }}\end{array}$ & $\begin{array}{l}\text { UA, } \\
\text { CPR, } \\
\text { UV }\end{array}$ & CTG & $1-56$ days & $\begin{array}{l}3-26 \\
\text { (At least 3) }\end{array}$ & $\begin{array}{l}\text { First measurement } \\
\text { abnormal }\end{array}$ & \begin{tabular}{|l|} 
CTG \\
Attending \\
obstetrician \\
discretion
\end{tabular} & $\begin{array}{l}\text { Patterns of progression: } \\
\text { GA at onset, interval to } \\
\text { delivery, progression } \\
\text { intervals }\end{array}$ & $\begin{array}{l}\text { According to the interval to to } \\
\text { delivery, a temporal sequence of } \\
\text { changes exist: 1-UA, 2-MCA, 3- } \\
\text { DV. }\end{array}$ \\
\hline 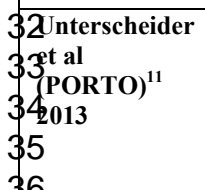 & \begin{tabular}{|l|}
7769 \\
exams, \\
1116 \\
patients
\end{tabular} & $\begin{array}{l}24-36 \text { at } \\
\text { first exam. } \\
\text { Interval of } \\
\text { exams not } \\
\text { indicated }\end{array}$ & $\begin{array}{l}\text { Not indicated } \\
\text { Mean and SD } \\
37.8+-3 \text { weeks }\end{array}$ & $\mathrm{EFW}<\mathrm{P} 10^{\text {th }}$ & $\begin{array}{lr}\text { UA, } & \text { MCA, } \\
\text { DV, } & \text { AoI, } \\
\text { MPI } & \end{array}$ & CTG & $1-14$ days & $\begin{array}{l}\text { Not } \\
\text { indicated }\end{array}$ & Not indicated & $\begin{array}{l}\text { CTG, } \\
\text { Attending } \\
\text { obstertician } \\
\text { discretion }\end{array}$ & $\begin{array}{l}\text { Frequencies for Doppler } \\
\text { deterioration sequences, } \\
\text { Cumulative } \\
\text { Frequencies of Doppler } \\
\text { anomalies, interval to } \\
\text { delivery }\end{array}$ & $\begin{array}{l}\text { Temporal sequence of changes like } \\
\text { 1-UA, 2-MCA, 3-DV does not exist } \\
\text { as other sequences present a similar } \\
\text { frequency }\end{array}$ \\
\hline $\begin{array}{l}39 \text { Morales- } \\
\text { 37Roselló et al } \\
38 \\
39 \\
40\end{array}$ & $\begin{array}{l}948 \\
\text { exams, } \\
405 \\
\text { fetuses }\end{array}$ & $24-33+6$ & $<37$ & $\begin{array}{l}\mathrm{EFW}<\mathrm{p} 10^{\text {th }} \\
\text { Suspicion of } \\
\text { SGA } \\
\text { Plus } \\
\text { BW }<\text { p10th }\end{array}$ & $\begin{array}{l}\text { UA, MCA, } \\
\text { DV }\end{array}$ & CTG & & $1-16$ & $\begin{array}{l}\text { First measurement } \\
\text { abnormal }\end{array}$ & \begin{tabular}{|l|} 
CTG, \\
Attending \\
obstetrician \\
discretion
\end{tabular} & $\begin{array}{l}\text { Frequencies for Doppler } \\
\text { deterioration sequences, } \\
\text { Cumulative } \\
\text { Frequencies of Doppler } \\
\text { anomalies, } \\
\text { interval to delivery }\end{array}$ & $\begin{array}{l}\text { Temporal sequence of changes: 1- } \\
\text { UA, 2-MCA, 3-DV exists. } \\
\text { UA-MCA-DV sequence occurs in } 2 \\
\text { thirds \% of cases. Interval to } \\
\text { delivery is shorter for the DV }\end{array}$ \\
\hline
\end{tabular}

4NOTES: UA: umbilical artery, MCA: middle cerebral artery, DV: ductus venosus, UV: umbilical vein, MPI: myocardial performance index, AoI: aortic isthmus, DT-Ao: 4 Alescending thoracic aorta, Ao-OT: aortic outflow tract, P-OT: pulmonary outflow tract, IVC: inferior vena cava, PI: pulsatility index, G: group, P: percentile, ${ }^{\dagger}$ cases with 2 43.rmalized MCA PI values were excluded, exam: examination, EFW: estimated fetal weight, CTG: cardiotocogram, BPS: biophysical score, GA: gestational age. 